\title{
Barriers to Accessing Emergency Medical Services in Accra, Ghana: Development of a Survey Instrument and Initial Application in Ghana
}

\author{
Nee-Kofi Mould-Millman, ${ }^{a}$ Sarah D Rominski, Joshua Bogus, ${ }^{c}$ Adit A Ginde, ${ }^{a}$ Ahmed N Zakariah, ${ }^{d}$ \\ Christiana A Boatemaah, ${ }^{d}$ Arthur H Yancey, ${ }^{e}$ Samuel Kaba Akoriyea, ${ }^{\text {d,f }}$ Thomas B Campbellg
}

\begin{abstract}
Most respondents thought the number of ambulances insufficient and said they would rather use a taxiperceived to be faster-in a medical emergency. Nevertheless, people generally had favorable attitudes of existing public ambulance services, although few knew of the toll-free emergency number and many thought it appropriate to use ambulances to transport corpses. Targeted public education, along with improved capacity of ambulance agencies to handle increased caseload, could improve use.
\end{abstract}

\section{ABSTRACT}

Background: Emergency medical services (EMS) systems provide professional prehospital emergency medical care and transportation to help improve outcomes from emergency conditions. Ghana's National Ambulance Service has relatively low public utilization in comparison with the large burden of acute disease.

Methods: A survey instrument was developed using Pechansky and Thomas's model of access covering 5 dimensions of availability, accessibility, accommodation, affordability, and acceptability. The instrument was used in a cross-sectional survey in 2013 in Accra, Ghana; eligible participants were those 18 years and older who spoke English, French, or Twi. Although the analysis was mainly descriptive, logistic regression was used to identify factors associated with reported intention to call for an ambulance in the case of a medical emergency.

Results: 468 participants completed surveys, with a response rate of $78.4 \%$. Few (4.5\%) respondents had ever used an ambulance in prior emergency situations. A substantial proportion (43.8\%) knew about the public access medical emergency telephone number, but of those only $37.1 \%$ knew it was a toll-free call. Most (54.7\%) respondents believed EMTs offered highquality care, but $78.0 \%$ believed taxis were faster than ambulances and $69.2 \%$ thought the number of ambulances in Accra insufficient. Many (23.4\%) thought using ambulances to transport corpses would be appropriate. In two hypothetical emergency scenarios, respondents most commonly reported taxis as the preferred transportation (see table at end of abstract). Those aged 18-35 years were more likely than older respondents to prefer an ambulance (odds ratio [OR], 2.27; confidence interval [Cl], 1.47 to 3.68), as were those with prior ambulance experience (OR, $1.75 ; \mathrm{Cl}, 0.98$ to 3.09 ) (compared with those with no prior experience) and those who believed ambulances were safer than taxis (OR, 2.17; $\mathrm{Cl}, 1.1$ to 4.2 ) (compared with those who did not hold such beliefs).

Conclusions: Perceptions of public ambulance services in Accra, Ghana, are generally favorable, although use is low. Public health education to improve awareness of the toll-free medical emergency number and about appropriate use of ambulances while simultaneously improving the capacity of ambulance agencies to receive increased caseload could improve use of the EMS system.

\footnotetext{
a University of Colorado School of Medicine, Department of Emergency Medicine, Aurora, CO, USA.

b University of Michigan Medical School, Global REACH, Ann Arbor, MI, USA.

'Washington University in Saint Louis, School of Medicine, Infectious Diseases Division, Saint Louis, MO, USA.

${ }^{\mathrm{d}}$ Ministry of Health Republic of Ghana, National Ambulance Service, Accra, Ghana.

${ }^{e}$ Emory University School of Medicine, Department of Emergency Medicine, Atlanta, GA, USA.

${ }^{f}$ Ghana Health Service, Institutional Care Division, Accra, Ghana.

g University of Colorado School of Medicine, Department of Medicine, Division of Infectious Diseases, Aurora, CO, USA.

Correspondence to Nee-Kofi Mould-Millman (Nee-Kofi.Mould-Millman@UCDenver.edu).
} 


\begin{tabular}{|lcccc|}
\hline & \multicolumn{4}{c|}{ Preferred Transportation } \\
\cline { 2 - 5 } Hypothetical Scenarios & Taxi & Ambulance & Any Available Vehicle & Other \\
\hline Family member burned & $63.6 \%$ & $20.7 \%$ & $15.5 \%$ & $0.2 \%$ \\
Pedestrian struck & $64.7 \%$ & $23.3 \%$ & $10.2 \%$ & $1.7 \%$ \\
\hline
\end{tabular}

\section{BACKGROUND}

E mergency medical services (EMS) are a community's gateway to acute and emergency medical care for members of the public facing timesensitive, condition-critical illness and injury. ${ }^{1,2}$ When implemented appropriately, EMS systems are an effective, frontline, public health intervention to reduce the disproportionately high morbidity and mortality in low- and middle-income countries. ${ }^{1,3,4}$ The formation of locally appropriate EMS systems in low-resource settings, to provide emergency care and transport, has been promoted by international bodies, such as the World Health Organization and the African Federation for Emergency Medicine. ${ }^{1,2,5,6}$

Thus, EMS systems, regardless of their state of development, play a critical role in the continuum of ensuing medical care. ${ }^{1,2,7}$ Emergency care usually begins in the community, when someone identifies a perceived emergency condition and attempts activation of the local EMS system. This ideally triggers a cascade of events resulting in a timely response of expertise, resources, and service directed to patient stabilization and/or safe emergency patient transportation to the nearest appropriate facility. ${ }^{1,2,5,8,9}$ The current norm in many low- and

Use of a private vehicle or taxi for transportation during an emergency is the current norm in many countries. middle-income countries is, however ironic, to use a private vehicle or a taxi to transport the injured or ill person to the hospital, even when EMS has an active presence in these communities. ${ }^{10,11}$

Across Africa, in-hospital and prehospital emergency care systems are being developed to serve diverse, multicultural, and multilingual populations of varying socioeconomic strata. ${ }^{2,6,12,13}$ For example, innovative programs in which motorbikes equipped with stretchers are activated in Malawi to transport emergency obstetric patients, and Ghana's National Ambulance Service (NAS) provides professional crews and time-sensitive emergency transportation for patients. ${ }^{9,14,15}$

Ghana boasts one of sub-Saharan Africa's thriving EMS systems. Formed in 2004, the NAS is comprised of a fully operational ambulance fleet with 160 basic life support-equipped ambulances and more than 1,200 emergency medical technicians (EMTs). It has a nationwide operational footprint, providing free emergency services to the citizens of Ghana. Within each of Ghana's 10 regional capitals in 2013, NAS had at least 1 ambulance station and several ambulances staffed by a crew of trained EMTs. Accra, the national capital, had the largest NAS complement of ambulances and personnel, with 8 ambulances and approximately 100 EMTs. ${ }^{16,17}$ Still, the Accra ambulance-to-population ratio is approximately $1: 250,000$ - a ratio that is $5-10$ times below expert-recommended ratios for lower-income countries-and the mean response time is about 18 minutes. ${ }^{16,17}$ Injuries are the most common reason for public utilization of NAS services. ${ }^{16,17}$ Despite sustained growth of NAS over the past decade, annual reports have indicated low public utilization, which may be a contributor to continued poor outcomes of acute care. The reasons behind low utilization have not been studied sufficiently., 16,17

This study was undertaken to characterize and quantify the range of barriers-from the demographic and psychosocial to the financial, knowledge, and cultural barriers - that prevent Ghanaian citizens in Accra from appropriately accessing local EMS resources. In Accra, we hypothesized low public opinion of ambulance services, poor knowledge of ambulance access, and thus a strong public preference to use non-ambulance means of transport during medical emergencies.

\section{METHODS}

\section{Conceptual Approach}

Pechansky and Thomas provide a conceptual framework of 5 dimensions that affect patient access to or entry into health care systems: availability, accessibility, accommodation, affordability, and acceptability (Box). ${ }^{18}$ Applications of this framework have elucidated causes for increased mortality pertaining to accessing emergency care, for emergency conditions such as sepsis and respiratory and obstetric emergencies. ${ }^{19-21}$ 
The domain of content and relevant elements for our survey instrument were identified by a multidisciplinary research team, including experts in emergency care, EMS, African public health, and survey design, following discussions and a review of the literature. Desired attributes of the survey instrument included comprehensiveness, simplicity in execution, standardized oral administration, and ease of comprehension by respondents, independent of their sociopolitical, cultural, and geographic background. The survey was designed to be delivered on a tablet computer (Nexus 7, Google Inc., USA) using survey software (droidSurvey 2013, Google Inc., USA) to facilitate data collection. The research team developed survey questions for each element. Most of these questions were structured to enable quantitative categorization of responses. Due to the exploratory nature of this research, openended questions were also included to promote less-restricted responses and provide a richer explanation of issues raised by respondents.

\section{Development and Validation of Survey Instrument}

The research team defined the domain of the survey as all citizen-perceived barriers potentially impeding EMS access in low-resource subSaharan African settings. Relevant elements to the domain were screened in the context of Pechansky and Thomas's domains of access (i.e., availability, accessibility, accommodation, affordability, and acceptability).

The survey instrument was written in English and designed to be orally administered to respondents by trained bilingual research assistants in English (the official language), French, or Twi (the most dominant local language). Each research assistant received more than 20 hours of training on the sampling technique and survey instrument, which included completing 15 supervised surveys each. The survey contained 8 main sections:

1. Respondent demographics

2. Prior experience(s) with EMS

3. Knowledge of ambulance function

4. Perceptions of ambulance performance

5. Hypothetical scenarios

6. Barriers to access

7. EMS educational intervention (in which we provided participants information about EMS)
8. Survey administration/logistics (e.g., interviewer name, location of survey, and language)

Of the 114 total questions, respondents were asked a maximum of 104, while 10 questions pertained to survey administration. The instrument had skip logic successfully embedded within it.

Early versions of the instrument underwent multiple rounds of revisions and sequential stages of validation. Three external survey experts provided feedback on its structure, including the syntax, grammar, and meaning of the chosen questions. Cognitive testing of a preliminary version of the instrument was performed in the United States (in Atlanta, Georgia, and in Ann Arbor, Michigan) and then in Ghana (in Accra and Kumasi) among 19 community members in total. During cognitive testing, feedback was provided on the meaning and clarity of questions, brevity, and ease of understanding and of responding to the survey. Pilot testing on the tablet computer was also conducted in Ghana, between April and June 2013, among 30 community members to ensure trouble-free data collection, to assess survey duration, and to resolve any impediments to conducting the survey.

According to the 49 community members and the 6 expert reviewers who participated in both phases of pilot testing and qualitative critique of the survey, the survey instrument passed face validity and content validity, and it was deemed

\section{BOX. Five Dimensions of Access to Health Care}

- Availability: the relationship of the volume and type of existing services (and resources) to the clients' volume and needs.

- Accessibility: the relationship between the location of supply of services (or resources) and the location of clients.

- Accommodation: the manner in which the services for resources) are organized to meet the needs of clients and clients' perceptions of the appropriateness of the way services are organized.

- Affordability: the relationship between the cost and perceived value of services and the clients' ability to pay.

- Acceptability: the relationship of the clients' perceptions and attitudes toward the service (or resources) to the actual characteristics of the service, as well as to the perceptions and attitudes of providers toward certain clients.

Source: Penchansky and Thomas. ${ }^{18}$ 
sound with regards to construct validity and translation. To test the instrument's consistency when administered by different surveyors, the instrument was tested by multiple surveyors over 2 days: 2 survey administrators on day 1 , and 3 survey administrators on day 2 . Interrater reliability measurements of key variables yielded Krippendorff's alpha scores between 0.66 to 1 , suggesting good to excellent interrater reliability. ${ }^{22,23}$ Intrarater and test-retest reliability were non-applicable because the EMS educational intervention (an integral part of the survey mission) would skew respondents' subsequent answers and introduce error into tests of reliability. All initially stated desired attributes were satisfied by the final design of the instrument.

\section{Sampling}

Surveys were conducted in a representative crosssection of the general public in Ghana's capital city, Accra, from June to August 2013. Accra is a coastal city in southern Ghana, and the metropolitan area had a population of approximately 1.8 million in 2012, distributed over 173 square kilometers. ${ }^{24,25}$

The rationale for selecting Accra was that the Accra metropolitan area has the highest concentration of NAS ambulances and the highest population volume and density in Ghana. ${ }^{26,27}$ Therefore, Accra qualified as a high-yield survey study site in which to reach an initial understanding of barriers to EMS access in the urban Ghanaian population.

To conduct balanced community-based random sampling, we replicated the population survey technique used in the 2003 and 2008 versions of the Ghana Demographic and Health Survey. ${ }^{28}$ In this approach, the Accra metropolitan area was divided into 11 geographic clusters, termed enumeration areas (Figure). To ensure valid statistical analysis could be conducted within each enumeration area, a target sample size of approximately 40 in each of the 11 areas was chosen, giving an overall sampling size of 440 .

Two research assistants (JB, CA) were trained by the study's lead investigators. The research assistants were fluent in English (both JB and CA), French (JB), and Twi (CA). In order to attain as broad a sample as possible, diverse areas including the road side, commercial areas, residential areas, schools, places of worship, and recreational areas were used as recruitment sites. By sampling every fifth person within each recruitment site and by using a goal of 6 to 8 interviews per site, an approximately equal number of people were interviewed within each enumeration area.

\section{Inclusion and Exclusion Criteria}

All persons 18 years of age and older, located within the 11 enumeration areas during our survey period, were eligible to participate after providing informed consent. Respondents who did not speak English, French, or Twi were excluded.

\section{Data and Statistical Analysis}

After we conducted the survey, we exported the data from the droidSurvey database into Microsoft Excel (2007, Redmond, WA). Quantitative data from closed-ended questions were cleaned and coded. Qualitative data from open-ended questions were reviewed by the authors and coded individually, into themes. Following initial coding, 2 authors (NM and SR) compared codes, discussed and resolved discrepancies, and categorized the codes into thematic areas. Missing data were noted as such, and no imputation was performed for missing variables. Cleaned and coded data were exported into a statistical software program, Stata (Stata Corp, College Station, TX), for analysis. Descriptive statistics were performed for quantitative data, using frequencies, means, and standard deviations (SDs), as appropriate.

In the survey, participants were presented with 2 hypothetical emergency situations and asked how they would prefer transport of the victim to the hospital. In the first scenario, the participant witnessed a pedestrian on the street struck by a car, implying accessibility to many private and commercial vehicles. In the second scenario, a relative was burned badly in a house fire, implying limited access to private or commercial vehicles. The primary outcome for regression analysis was the response to the question, "If you saw a pedestrian hit by a car and they needed to go to a hospital immediately, how would you get them to the hospital?" Answers were categorized, then dichotomized to "ambulance" (combining the NAS ambulance and other ambulance options) and "non-ambulance," then were analyzed using logistic regression.

An analytic model was developed to assess the effect of independent variables on this primary outcome variable. Independent variables in our model included respondent's age, sex, education level, prior experience with ambulances, knowledge of local ambulance services, knowledge 
FIGURE. Survey Locations Within the 11 Demographic and Health Survey Enumeration Areas for Accra, Ghana

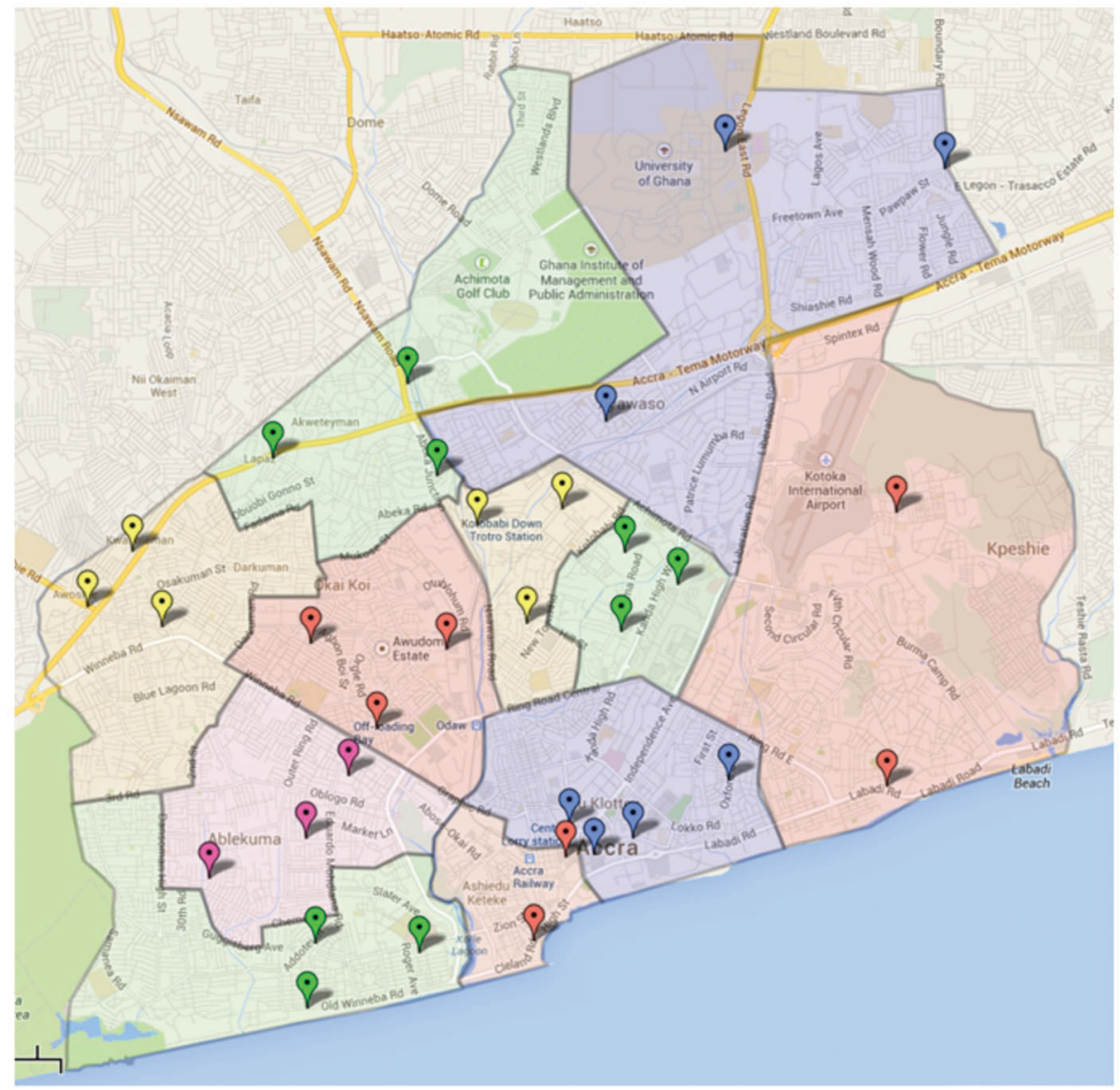

of appropriate ambulance functions, and knowledge of the local emergency access number, all of which were assessed as part of the survey. To explore the relationship between independent variables and the outcome variable (decision to call an ambulance), descriptive cross tabs with chi-square analysis were performed. Variables were selected according to previous literature and the expert opinion of the authors. Variables that were found to be significant in bivariate analysis at the 0.1 level were entered into a multivariate model.

\section{Ethical Approval}

Ethical approval was obtained from the following human subjects committees: Colorado Multiple
Institutional Review Board, University of Michigan Institutional Review Board, and the Ghana Health Service Ethical Review Committee.

\section{RESULTS}

Of 597 people who were approached, 468 completed the survey, yielding a survey response rate of $78.4 \%$. Almost all ( $>90 \%$ ) persons who refused participation did not give a reason for why they declined to consent. Respondents were sampled from all 11 enumeration areas, with between 38 and 57 respondents in each area. The majority of the respondents were surveyed in business locations $(n=204,43.6 \%)$, followed by the street $(n=135,28.8 \%)$ and residential 
While $75 \%$ of respondents had had a prior experience with an emergency incident, only $5 \%$ had ever used an ambulance. locations $(n=89,19.0 \%)$. The remainder $(n=33$, $7.1 \%$ ) were surveyed in locations coded as "other," mainly postgraduate schools, such as law school. Location data were missing for 7 participants $(0.85 \%)$. Most of the surveys were conducted in English $(\mathrm{n}=273,58.3 \%)$, but a substantial proportion were translated $(\mathrm{n}=195$, $40.2 \%)$, virtually all in Twi ( $\mathrm{n}=184$ in Twi, $\mathrm{n}=1$ in French, $\mathrm{n}=10$ not documented).

\section{Background Demographic Characteristics}

Slightly more than half of the participants who completed the survey were men $(n=248,53.0 \%)$ (Table 1). The mean age was 34.9 years (SD, 12.9), with the majority $(n=277,59.2 \%)$ of respondents between $18-35$ years. The large majority $(n=448$, 95.7\%) resided in the Accra metropolitan area. Only 53 participants $(11.3 \%)$ owned a car, but $453(96.8 \%)$ owned a cell phone. About one-third $(n=159,34.0 \%)$ of the respondents had attained post-secondary education.

\section{Prior Ambulance Use}

In the preceding 5 years, $350(74.8 \%)$ respondents had had a personal experience and/or had witnessed an experience with either or both a medical $(n=246,57.7 \%)$ or traumatic $(n=205$, $47.1 \%$ ) incident that required acute or emergency care. Of those prior incidents requiring acute or emergency care, $402(89.1 \%)$ resulted in

TABLE 1. Demographic Characteristics of Survey Respondents, Accra, Ghana (N=468)

\begin{tabular}{lclc}
\hline & No. (\%) & & No. (\%) \\
\hline Sex & & Ewe & $85(18.1)$ \\
Male & $248(53.0)$ & Hausa & $73(15.6)$ \\
Female & $220(47.0)$ & Other & $145(31.0)$ \\
Age, $\mathbf{y}$ & & Education & \\
$18-35$ & $277(59.2)$ & None & $32(6.8)$ \\
$36-50$ & $128(27.3)$ & Primary & $108(23.1)$ \\
$51+$ & $63(13.5)$ & Secondary & $167(35.7)$ \\
Residence & & Technical & $19(4.1)$ \\
Accra metropolitan area & $448(95.7)$ & Certificate & $66(14.1)$ \\
Other & $20(4.3)$ & Diploma & $26(5.6)$ \\
Cell phone ownership & & University & $42(9.0)$ \\
Yes & $453(96.8)$ & Post-University & $6(1.3)$ \\
No & $15(3.2)$ & Missing & $2(0.4)$ \\
Car ownership & & Occupation & \\
Yes & $53(11.3)$ & Service and sales worker & $231(49.4)$ \\
No & $415(88.7)$ & Student & $83(17.7)$ \\
Languages spoken ${ }^{a}$ & & Craft and related trade & $54(11.5)$ \\
Twi & $413(88.2)$ & Technicians and associated profession & $37(7.9)$ \\
English & $391(83.5)$ & Industrial and machinery operator & $15(3.2)$ \\
Ga & $220(47.0)$ & Other & $48(10.3)$ \\
\hline a Percentages do not total to 100\%, given multilingual & respondents. & \\
& & &
\end{tabular}


transportation to the hospital. Only 18 (4.5\%) respondents had ever used an ambulance in the emergency situation (Table 2). The rest of respondents had used taxis $(n=195,48.5 \%)$, private cars $(n=49,12.2 \%)$, or other $(n=112,27.9 \%)$ forms of transportation. Of the 18 respondents who recalled using an ambulance, 4 (22.2\%) had called the public access emergency medical number and the rest $(n=14,77.8 \%)$ had used alternative means to access the service (data not shown). In total, 69 (14.7\%) respondents recalled being inside an ambulance in the past 5 years.

\section{Knowledge and Perceptions of Ambulance Services}

Table 3 details respondents' knowledge and perceptions of ambulance services in Ghana, according

TABLE 2. Prior Experiences in Past 5 Years With Transportation During an Emergency Among Survey Respondents $\left(\mathrm{N}=350\right.$ Respondents for a Total of 402 Incidents) ${ }^{a}$

\section{Type of Emergency}

Injury, No. (\%) Illness, No. (\%)

Total, No. (\%)

Type of transportation to hospital used

Ambulance

Taxi

Private car

Tro-Tro (minibus)

Motorbike

Walked

Don't remember

Missing

TOTAL

\section{How transportation was accessed}

Waved down taxi

Someone waved taxi

Walked to ambulance station

Used own car/family drove

Shouted/yelled for help

Called known contact

Sent someone to find transport

Went myself to find transport

Health care provider called transport for me

Don't remember

Missing

TOTAL

$$
\begin{gathered}
15(9.6) \\
85(54.5) \\
22(14.1) \\
8(5.1) \\
4(2.6) \\
2(1.3) \\
6(3.8) \\
14(9.0)
\end{gathered}
$$

$156(38.8)$

$5(4.1)$
$14(11.5)$
$1(0.8)$
$2(1.6)$
$19(15.6)$
$4(3.3)$
$42(34.4)$
$9(7.4)$
$0(0.0)$
$11(9.0)$
$15(12.3)$
$22(37.1)$

$3(1.2)$

110 (44.7)

27 (11.0)

60 (24.4)

$0(0.0)$

38 (15.4)

7 (2.8)

$1(0.4)$

246 (61.2)

$0(0.0)$

$0(0.0)$

$0(0.0)$

$0(0.0)$

$0(0.0)$

30 (14.5)

54 (26.1)

114 (55.1)

2 (1.0)

6 (2.9)

$1(0.5)$

207 (62.9)
18 (4.5)

195 (48.5)

49 (12.2)

68 (16.9)

4 (1.0)

40 (10.0)

13 (3.2)

15 (3.7)

402 (100)

14 (4.3)

$1(0.3)$

$2(0.6)$

$19(5.8)$

$34(10.3)$

$96(29.2)$

$123(37.4)$

$2(0.6)$

17 (5.2)

$16(4.9)$

$329(100)$

${ }^{a}$ Respondents could have experienced either a traumatic (injury) or medical (illness) emergency or both. 
TABLE 3. Knowledge and Perceptions of Ambulance Services Among Survey Respondents ( $N=468$ )

No. $(\%)$

No. $(\%)$

\section{Availability}

Knew at least one ambulance company

Knew about government ambulance service

Able to name the National Ambulance Service (NAS)

Thought the number of ambulances in Accra insufficient

\section{Accessibility}

Knew about public emergency access number

Knew public access number is $1-9-3$

Expected NAS ambulance response time during peak traffic hours

$\leq 15$ minutes

Between 16 and 59 minutes

$\geq 60$ minutes

Expected NAS ambulance response time during non-peak traffic hours

$\leq 15$ minutes

Between 16 and 59 minutes

$\geq 60$ minutes

\section{Accommodation $^{\mathrm{a}}$}

Identified at least one appropriate indication (as defined by NAS) for accessing an ambulance

Thought use of ambulance to transport corpses would be appropriate

Thought ambulances in Accra were currently being used to:

Transport persons with medical illnesses

$223(48.4)$

Transport injured people

$161(34.9)$

Conduct interfacility transfers

$213(45.5)$

$26(5.6)$

$324(69.2)$

$205(43.8)$

$16(3.4)$

$165(35.3)$

$271(57.9)$

$32(6.8)$

$311(66.5)$

$154(32.9)$

$3(0.6)$

$444(96.3)$

$108(23.4)$

$\mathrm{N}=461$ as there were 7 missing tresponses.

$90(19.5)$
425 (90.8) Respondents who knew of the public emergency number $(n=205)$ and thought the cost of calling that number was:
Free (i.e., toll free)

Same as a regular call

Less expensive than a regular call

More expensive than a regular call

Did not know the cost

More likely to call 1-9-3 in an emergency if the call was free

$167(35.7)$

Thought the cost of government ambulance service was:

Free

$14(3.0)$

Affordable

$235(50.2)$

Too expensive

$10(2.1)$

Thought the cost of private ambulance service was:

Cheap

Affordable/reasonable

$16(3.4)$

Too expensive

$235(50.2)$

Did not know

$206(44.0)$

\section{Acceptability}

Believed ambulance technicians in

$256(54.7)$

Accra offered high-quality care

Believed it is safer to go to the hospital

$378(80.8)$ by ambulance than by taxi in Accra

Believed it is faster to go to the hospital 365 (78.0) by taxi than by ambulance in Accra

Believed it is "better" to go to the hospital by ambulance than by taxi in $403(86.1)$ 
to the 5 dimensions of access defined by Pechansky and Thomas.

\section{Availability}

$213(45.5 \%)$ respondents knew specifically about the government ambulance service, but only $26(5.6 \%)$ correctly knew it was called the National Ambulance Service. The majority $(\mathrm{n}=324,69.2 \%)$ thought there was an insufficient number of ambulances in Accra.

\section{Accessibility}

205 (43.8\%) knew the existence of a public access medical emergency telephone number (1-9-3). During peak traffic hours, 165 (35.3\%) of the respondents indicated that it would take a government ambulance (NAS) 15 minutes or less to arrive at the location of their incident, while $32(6.8 \%)$ stated it would take 60 minutes or more.

\section{Accommodation}

To gauge participants' perceptions of the client needs that ambulance services were currently organized to meet, we asked participants what they perceived ambulance services were currently used for in Ghana. Eight general themes emerged, centered around providing care and transportation to: (1) people with medical emergencies, (2) people with injuries, (3) burn victims, (4) obstetric patients in labor or with complications, (5) those with other emergency conditions, (6) patients requiring interfacility transportation, (7) provide general prehospital emergency care to the population, and (8) provide other specialized services. Participants most commonly reported that ambulances were currently used as transportation for medical illnesses $(n=223,48.4 \%)$, for injuries $(n=161,34.9 \%)$, and for interfacility transfers $(n=90,19.5 \%)$. A substantial number $(\mathrm{n}=108,23.4 \%)$ thought ambulances should be used as hearses to transport dead bodies (but NAS policies do not permit or accommodate this). Selected responses from the open-ended question, "What are ambulances currently used for in Ghana?", are listed in Table 4.

\section{Affordability}

Of those respondents who knew the existence of a public-access number for medical emergencies, only $76(37.1 \%)$ knew it was a toll-free call. About one-third $(n=167,35.7 \%)$ of all the respondents indicated they would be more likely to call the 1-9-3 number in an emergency if they knew the call was toll free. When asked about their perceived cost of ambulances as a potential barrier, the majority of subjects indicated that government ambulances were free or affordable $(\mathrm{n}=249,53.2 \%)$ and that private ambulances were too expensive $(n=235,50.2 \%)$.

\section{Acceptability}

The majority $(\mathrm{n}=256,54.7 \%)$ believed the EMTs offer high-quality care, and most ( $\mathrm{n}=403,86.1 \%)$ believed it is overall "better" to go by ambulance in an emergency. However, the majority also thought taxis are faster than ambulances in Accra $(n=365,78.0 \%)$.

\section{Hypothetical Scenarios}

Of the 459 total responses to both hypothetical questions, $57(12.4 \%)$ respondents reported they would call for an ambulance (either NAS or other) in both hypothetical scenarios (witnessing a pedestrian severely struck by a vehicle and a family member being burned badly in a house fire) (Table 5). The most common response was to use a taxi in both scenarios $(\mathrm{n}=225,49.0 \%)$ while $21 \quad(4.6 \%)$ stated they would take any available vehicle as a means of emergency transportation in both events.

An analytic model was developed in which the likelihood of calling an ambulance after witnessing a pedestrian-auto collision (outcome variable) was assessed as a function of respondent demographics of age, sex, education level, cell phone ownership, car ownership, prior ambulance experience, knowledge of ambulance function, knowledge of cost of the 1-9-3 call, and perception of ambulances (safe, fast, better). Age of respondent (in years) was found to be negatively associated with the likelihood of calling for an ambulance (Table 6). This response was then categorized into 3 age variables: 18-35, $36-50$, and over 51 years. Being between the ages of 18 and $35(P=.01)$ and believing ambulances were safe means of emergency transport $(P=.02)$ were significantly associated with reported likelihood of respondents to call for an ambulance in the case of an emergency. Prior experience with an ambulance $(P=.06)$ was positively associated with likelihood of calling for an ambulance, but the association was not statistically significant. Those respondents aged 18-35 were 2.3 times as likely to call for an ambulance (odds ratio [OR], 2.27) as older respondents, and those who believed an ambulance is safer than a taxi were over 2 times as likely to report they would call for an ambulance (OR, 2.17) as those who did not hold such beliefs, while those who had personal experience with an ambulance were $75 \%$ more likely to report they would call for an ambulance than those with no prior experience

\section{$69 \%$ of} respondents thought the number of ambulances in Accra insufficient.

\section{In hypothetical emergency scenarios, respondents most commonly reported taxis as the preferred transportation mode.}


TABLE 4. Selected Responses About Current Use of Ambulances in Ghana According to Appropriateness of the Use Appropriate Use of Ambulance Inappropriate Use of Ambulance

"Because it is an emergency the ambulance is necessary since it will get to hospital faster than taxi."

"I think the ambulance is to be for the dead ... the sick and the injured should have their own special car."

"Ambulances should be used to help those in need of health care, because we do not have enough hospitals and the ambulances can provide first aid."

"For the corpse you can only use the ambulance, the police will arrest you if you take a dead body in another vehicle."

"That is the job of the ambulance to save life because they have first aid in the ambulance to help you before getting to hospital."

"Ambulances should be used to pick up the sick in the communities, but the government does not have enough so we use taxis."

"The ambulance is supposed to be there for emergencies at home, schools, and everywhere."

"Because there are not enough ambulances we only use the ambulance for emergencies, but if there were enough then we should use ambulances for critical illness."

\begin{abstract}
"For the pregnant women in labor it is better to go by taxi to get to the hospital quickly"
\end{abstract}

"It is not nice to put a corpse in a regular car."

"That is what I have seen the ambulances do. I fear the dead so I could not be in the same car that has carried the dead so corpses should be carried in an ambulance."

"The ambulance should be able to convey even those with mild sickness ..."
(OR, 1.75). No other statistically significant association was discovered between any other variable and likelihood of calling an ambulance in the pedestrian injury scenario.

A similar regression was repeated using the second hypothetical scenario (in which a family member was burned in a house fire), with the respondents' answers to how they would transport that patient to the hospital as the outcome variable, while maintaining the original independent variables (listed above). Results were similar (data not presented).

\section{DISCUSSION}

Although the significant burden of acute disease in Ghana suggests a large need for ambulance services, calls for ambulances from the public are

TABLE 5. Transportation Preferences in Hypothetical Emergency Scenarios: Concordance in Survey Responses to Both Scenarios ( $N=459$ Responses)

Preferred Transportation if Family Member Burned, No. (\%)

\begin{tabular}{lcccccc}
$\begin{array}{l}\text { Preferred Transportation if Pedestrian } \\
\text { Struck, No. (\%) }\end{array}$ & $\begin{array}{c}\text { NAS } \\
\text { Ambulance }\end{array}$ & $\begin{array}{c}\text { Other } \\
\text { Ambulance }\end{array}$ & Taxi & $\begin{array}{c}\text { Any Available } \\
\text { Vehicle }\end{array}$ & $\begin{array}{c}\text { Tro-Tro } \\
\text { (minibus) }\end{array}$ & Total \\
\hline NAS ambulance & $5(1.1)$ & $1(0.2)$ & $4(0.9)$ & $2(0.4)$ & $0(0.0)$ & $\mathbf{1 2 ( 2 . 6 )}$ \\
Other ambulance & $18(3.9)$ & $33(7.2)$ & $37(8.1)$ & $7(1.5)$ & $0(0.0)$ & $\mathbf{9 5 ( 2 0 . 7 )}$ \\
Taxi & $13(2.8)$ & $17(3.7)$ & $225(49.0)$ & $41(8.9)$ & $1(0.2)$ & $\mathbf{2 9 7}(64.7)$ \\
Any available vehicle & $0(0.0)$ & $7(1.5)$ & $19(4.1)$ & $21(4.6)$ & $0(0.0)$ & $\mathbf{4 7}(10.2)$ \\
The car that hit the pedestrian & $0(0.0)$ & $1(0.2)$ & $7(1.5)$ & $0(0.0)$ & $0(0.0)$ & $\mathbf{8 ( 1 . 7 )}$ \\
Total & $\mathbf{3 6 ( 7 . 8 )}$ & $\mathbf{5 9 ( 1 2 . 9 )}$ & $\mathbf{2 9 2 ( 6 3 . 6 )}$ & $\mathbf{7 1 ( 1 5 . 5 )}$ & $\mathbf{1}(\mathbf{0 . 2})$ & $\mathbf{4 5 9 ( 1 0 0 . 0 )}$
\end{tabular}

Abbreviation: NAS, National Ambulance Service. 
disproportionately lower., ${ }^{9,15,16,29}$ Our study has elucidated contributing factors to this issue in Accra, where study participants most commonly indicated they would call a taxi-perceived to be faster than ambulances-in hypothetical traumatic emergency situations. The majority of participants thought there was an insufficient number of ambulances. Yet most participants had favorable opinions of existing ambulances, indicating they provided high-quality care and that they were safer and ultimately better than taxis. Only a minority, however, knew of the toll-free public access number, and many thought that ambulances should be used to transport corpses. With awareness of proper use of ambulance services and how to access it, along with adequate numbers of ambulances per population, use of ambulance services in emergency medical situations may improve. Our main findings, interpretations, and their significance are discussed below in the context of respondents' prior experiences, preferences, and perceived barriers and facilitators.

\section{Prior Emergency Medical Experiences and Use of Ambulance Services}

Up to $75 \%$ of respondents reported experiencing a medical or traumatic emergency within the preceding 5 years. Among these, only about 5\% had used an ambulance for emergency transportation to a health care facility. This is a lower proportion of ambulance use than was found in prior studies in Ghana that indicated ambulance use by the general population in $8 \%$ to $12 \%$ of emergencies. ${ }^{9111}$ This difference may be accounted for by respondent recall bias, although we do acknowledge that emergency situations are often major life events and less likely forgotten; however, we have no way to assess to what extent participants were accurately recalling events. In addition, this study excluded cases of interhospital ambulance transfers, which are relatively common in Ghana and were included in prior studies. ${ }^{9,11,16}$ Nonetheless, the results confirm a generally low rate of ambulance access requests and utilization for medical and traumatic emergencies in a resource-constrained African setting.

\section{Preferences for Modes of Emergency Transportation}

When presented with the study's hypothetical emergency injury scenarios (pedestrian hit by a car and person burned in a house fire), relatively few (12\%) Ghanaians stated they would call for an ambulance in both scenarios, while $49 \%$ said they

\section{TABLE 6. Likelihood of Calling an Ambulance in Hypothetical Pedestrian-Auto Collision: Results of Logistic Regression Analysis

\begin{tabular}{lcc}
\hline & OR $(95 \%$ CI) & P Value \\
\hline Personal experience with ambulance & $1.75(0.98,3.09)$ & .06 \\
Aged 18-35 & $2.28(1.47,3.68)$ & .001 \\
Believe ambulance safer than taxi & $2.17(1.12,4.19)$ & .02 \\
\hline
\end{tabular}

Abbreviations: $\mathrm{Cl}$, confidence interval; $\mathrm{OR}$, odds ratio.

would rather use a taxi in both scenarios. These findings may be explained by the fact that $75 \%$ of respondents perceived taxis to be a "faster" form of prehospital transport than ambulances. Although there is no prior research assessing taxi response times in Ghana, given the ubiquitous presence of taxis and relative paucity of ambulances in 2013, it seems reasonable to assume a faster response time from the former. ${ }^{16}$ Paradoxically, respondents generally had favorable opinions of existing ambulance services in Accra: over half (55\%) felt that EMTs offer "high-quality" care, 81\% acknowledged that ambulances were in fact the "safer" form of emergency transport, and $86 \%$ affirmed that ambulances were ultimately the "better" way to be transported during emergencies. However, $69 \%$ of our sample felt the number of ambulances in the Accra metropolitan area insufficient. This leads to the inference that when an adequate number of ambulances exists, and citizens are made aware of this service, individuals (who appear to generally understand the appropriate indications to access an ambulance) may be inclined to actively seek access to them more often for primary, or scene, responses. Of note, given the high percentage of respondents who indicated some preference for taxis, a complementary, practical non-ambulance solution for safer emergency transport may include mass training of taxi drivers in first aid, appropriate destination hospital selection, and safe emergency transport (successfully demonstrated by Mock et al. in a small pilot study in Kumasi, Ghana, in the 1990s). ${ }^{9,10}$

\section{Perceived Barriers and Facilitators to Accessing Ambulances}

Although 44\% of respondents who knew the existence of a public access number in Accra, only $37 \%$ knew it was toll free, and 36\% stated they would be more likely to call if they knew the call was free. Half believed NAS (the government ambulance service) was affordable, but very few 
(3\%) knew it was a free service. Misperceptions about telephone access and cost of ambulance services are indicative of a general paucity of education among Ghanaians in Accra, and this is most likely generalizable to citizens across the nation. Issues within Ghana that focus on telephonebased access to emergency medical services through emergency medical dispatch are the subject of a parallel study by the investigators of this study.

We demonstrated that those with prior personal experience with an ambulance service, who were younger in age, or who believed ambulances to be a safer means of transport were more likely to report they would call for an ambulance in the event of a medical emergency.

Several previously hypothesized barriers were not perceived by our participants as obstacles to accessing EMS services, including poor knowledge of ambulance companies and appropriate indications to access ambulances. Over $90 \%$ of respondents were aware of the existence of at least one ambulance company in Accra, and about half knew specifically of NAS. Over $90 \%$ of surveyed citizens knew at least one appropriate indication for accessing an ambulance. Interestingly, 23\% of respondents also inappropriately suggested that ambulances in Ghana should be used to transport corpses, a long-standing accepted practice in Ghana that was outlawed in 2012. This warrants special mention as many respondents felt ambulances were generally vehicles for transporting corpses, a common misperception that may prevent appropriate ambulance access. This deep-rooted sociocultural perspective may persist until this historic practice is completely

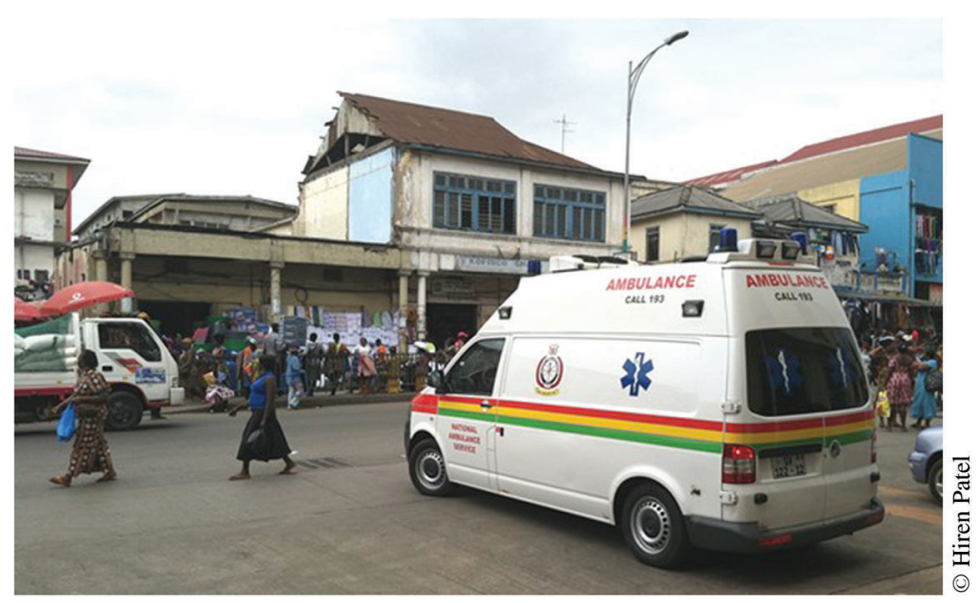

A NAS ambulance on standby at a busy marketplace in central Accra, Ghana. aborted in Ghana and purposeful public information reverses the misperception.

Prior to this study, only one published report in the African emergency care literature was found that sought to assess barriers to accessing prehospital emergency care by a medically undifferentiated population. ${ }^{30}$ That study was undertaken in Libreville, Gabon, in 2009, where investigators conducted a brief 9-question oral interview of a small $(\mathrm{N}=25)$ convenience sample of patients and visitors at a local emergency center. Qualitative results from this study indicated that misperceptions, lack of awareness, alternative forms of transport, and cost were all barriers to accessing prehospital resources. While our results support many of these findings, cost does not appear to be as substantial a barrier as in this previous study. Further, the majority of our study's population had high awareness of the service and confidence in the service's care and safety. However, the specifics about how to access the service, indicated by the low prevalence of awareness of the free public access phone number, reflect a population-based problem of access to care in Ghana.

\section{Possible Interventions to Improve Use of Ambulance Services}

If the culture of seeking formal emergency transportation and professional prehospital medical care does not shift among populations, EMS systems risk failing in their mission to save lives when timesensitive expertise-driven care is required. Fortunately, our findings bear favorable implications for public health education as a means to appropriately improve access to and use of ambulance services in Ghana, given the preponderance of short-term modifiable factors. For example, focused public education about the toll-free number, ambulance safety, and response or transport times, delivered via media consumed by persons aged 18-35, may be one highyield targeted method to improve appropriate public ambulance utilization, once adequate ambulance response units exist in the near future. This may be accomplished as part of public media campaigns and/or incorporated into school-based education. However, there has purposefully been no large-scale public educational efforts by the Ghana Ministry of Health or NAS given the small capacity of this ambulance service relative to its large jurisdictional responsibility.

It is noteworthy that while the development of an EMS system is important and prehospital care confers a survival benefit, there must be concurrent 
improvement in in-hospital emergency care to synergistically improve patient outcomes. Emergency medicine is a recognized medical specialty in Ghana, and while specialist training has been ongoing in Kumasi, it is yet to commence in Accra where there is a paucity of emergency medicine specialist physicians. ${ }^{9,15}$

\section{Adaptation of the Survey Instrument}

While this survey instrument was designed for application in Ghana, plans are underway to adapt it to other African settings in which EMS leaders, administrators, and researchers desire to scientifically understand and quantify barriers to access of their local emergency medical services in order to increase the public's appropriate use of EMS services.

\section{Limitations}

We do note heavier sampling in business and academic centers, which may have introduced a selection bias toward more-educated individuals, thereby making our sample less representative of the Accra population. Analysis of the Accra study population's demographics indicate a high similarity to the general Ghanaian population; however, our conclusions are less generalizable to other urban areas in Ghana and least generalizable to non-urban areas in Ghana. Further, recall bias and decisions based on hypothetical emergency situations do not necessarily correlate with actual practice, and this is an unavoidable shortcoming in a survey.

\section{CONCLUSIONS}

Across Africa, EMS systems are developing rapidly in an effort to address the large burden of growing acute injury and endemic disease. This article describes the first known successful development and application of a robust community-based survey instrument to quantify the demographic, perceptual, and experiential factors that may prevent an African subpopulation from accessing critical EMS resources. Findings from this novel study indicate generally favorable perceptions of public ambulance services in Accra. Once ambulance agencies are operationally poised to receive an increased call volume and caseload, public education should be targeted to address selected topics, for example, to improve awareness of the toll-free public access number and about the inappropriateness of transporting corpses, thereby positively influencing citizens' decisions to call for an ambulance. The present findings also support consieration of reconfiguring the public ambulance service to encompass trained taxi services as firstresponders, which has been previously pilot tested in Ghana with operational and educational success.

Future work will include deploying the survey in rural Ghanaian settings and other African countries developing EMS systems.

Acknowledgments: The investigator team wishes to acknowledge and thank personnel of the National Ambulance Service, Shakiyla Smith of Emory University Department of Emergency Medicine, and Alannah Kittle of Emory University, Rollins School of Public Health, for their support in the design, planning, and conduct of this study.

Competing Interests: None declared.

\section{REFERENCES}

1. Kobusingye OC, Hyder AA, Bishai D, Joshipura M, Hicks ER, Mock C. Emergency medical services. In: Jamison DT, Breman JG, Measham AR, Alleyne G, Claeson M, Evans DB, et al., editors. Disease control priorities in developing countries. 2nd ed. Washington (DC): World Bank; 2006. Available from: http://wnw.ncbi.nlm.nih.gov/books/ NBK11744/

2. Mould-Millman NK, Naidoo R, de Vries S, Stein C, Wallis LA. AFEM Consensus Conference, 2013. AFEM Out-of-Hospital Emergency Care Workgroup Consensus Paper: advancing outof-hospital emergency care in Africa-advocacy and development. Afr J Emerg Med. 2014 Jun;4(2):90-95. CrossRef

3. Razzak JA, Kellermann AL. Emergency medical care in developing countries: is it worthwhile? Bull World Health Organ. 2002;80(1 1):900-905. Medline

4. Henry JA, Reingold AL. Prehospital trauma systems reduce mortality in developing countries: a systematic review and metaanalysis. J Trauma Acute Care Surg. 2012;73(1):261-268. CrossRef. Medline

5. Sasser S,Kellermann AL,Lormand J-D, editors. Prehospital trauma care systems. Geneva: World Health Organization; 2005. Available from: http://www.who.int/violence_injury_prevention/ publications/services/04_07_2005/en/

6. Calvello E, Reynolds T, Hirshon JM, Buckle C, Moresky R, O’Neill J, et al. Emergency care in sub-Saharan Africa: results of a consensus conference. Am J Emerg Med. 2013;3(1):42-48. CrossRef

7. Mould-Millman NK, Sun J. The African trauma chain of survival: proposing a model of integrated care. Ann Glob Health. 2014;80(3):219-220. CrossRef

8. Mock C, Lormand JD, Goosen J, Joshipura M, Peden M. Guidelines for essential trauma care. Geneva: World Health Organization; 2004. Available from: http://apps.who.int/iris/ bitstream/10665/42565/1/9241546409_eng.pdf

9. Nee-Kofi Mould-Millman C, Rominski S, Oteng R. Ambulance or taxi? High acuity prehospital transports in the Ashanti region of Ghana. Am J Emerg Med. 2014;4(1):8-13. CrossRef

10. Tiska MA, Adu-Ampofo M, Boakye G, Tuuli L, Mock CN. A model of prehospital trauma training for lay persons devised in Africa. Emerg Med J. 2004;21(2):237-239. CrossRef. Medline

11. Abstracts of scientific papers 19th world congress on disaster and emergency medicine. Bonney J. How did you get here? An assessment of the mode of transport used by referred cases arriving at the emergency department (ED) of the Komfo Anokye Teaching Hospital (KATH), Kumasi, Ghana. Prehosp Disaster Med. 2015;30 Suppl 1:S1-S170. CrossRef. Medline 
12. Nielsen K, Mock C, Joshipura M, Rubiano AM, Zakariah A, Rivara F. Assessment of the status of prehospital care in 13 low- and middle-income countries. Prehosp Emerg Care. 2012;16(3):381-389. CrossRef. Medline

13. Mould-Millman NK, Sasser SM, Wallis LA. Prehospital research in sub-saharan Africa: establishing research tenets. Acad Emerg Med. 2013;20(12):1304-1309. CrossRef. Medline

14. Hofman JJ, Dzimadzi C, Lungu K, Ratsma EY, Hussein J. Motorcycle ambulances for referral of obstetric emergencies in rural Malawi: do they reduce delay and what do they cost? Int J Gynaecol Obstet. 2008;102(2):191-197. CrossRef. Medline

15. Osei-Ampofo M, Oduro G, Oteng R, Zakariah A, Jacquet G, Donkor $P$. The evolution and current state of emergency care in Ghana. Am J Emerg Med. 2013;3(2):52-58. CrossRef

16. Mould-Millman C, Oteng R, Zakariah A, Osei-Ampofo M, Oduro G, Barsan $W$, et al. Assessment of emergency medical services in the Ashanti region of Ghana. Ghana Med J. 2015;49(3):125-135. CrossRef

17. National Ambulance Service. 2012 annual report. Accra (Ghana): Ministry of Health [Ghana]; 2013.

18. Penchansky R, Thomas JW. The concept of access: definition and relationship to consumer satisfaction. Med Care. 1981;19(2):127-140. CrossRef. Medline

19. Chaudhary T, Hohenstein C, Bayer O. [The golden hour of sepsis: initial therapy should start in the prehospital setting]. Med Klin Intensivmed Notfmed. 2014;109(2):104-108. German. CrossRef. Medline

20. Schmidbauer W, Stuhr M, Veit C, Hölldobler G, Kerner T. [Sepsis in emergency medicine--pre-hospital and early in-hospital emergency treatment]. Anästhesiol Intensivmed Notfallmed Schmerzther. 2013;48(9):524-530; quiz 532. German. CrossRef. Medline
21. Barriot P, Riou B. Prevention of fatal asthma. Chest. 1987; 92(3):460-466. CrossRef. Medline

22. Landis JR, Koch GG. The measurement of observer agreement for categorical data. Biometrics. 1977;33(1):159-174. CrossRef. Medline

23. Hayes AF, Krippendorff K. Answering the call for a standard reliability measure for coding data. Commun Methods Meas. 2007;1(1):77-89. CrossRef

24. Ghana Statistical Service (GSS). Population by region, district, age groups and sex, 2010 [Internet]. 2012 Oct [cited 2014 Jul 11]. Available from: http://www.statsghana.gov.gh/docfiles/ pop_by_region_district_age_groups_and_sex_2010.pdf

25. Accra Metropolitan Assembly (AMA). The composite budget of the Accra Metropolitan Assembly for the 2012 fiscal year. Accra: AMA; 2012. Available from: http://www.mofep.gov.gh/sites/ default/files/budget/AMA.pdf

26. National Ambulance Service. 2010 annual report. Accra (Ghana): Ministry of Health [Ghana]; 2011.

27. Ghana Statistical Service (GSS). 2010 population and housing census: national analytical report. Accra (Ghana): GSS; 2013. Available from: http://www.statsghana.gov.gh/docfiles/ 2010phc/National_Analytical_Report.pdf

28. Ghana Statistical Service (GSS); Ghana Health Service (GHS); ICF Macro. Ghana demographic and health survey 2008. Accra (Ghana): GSS; 2009. Co-published by GHS and ICF Macro. Available from: http://dhsprogram.com/pubs/pdf/FR221/ FR221\%5B13Aug2012\%5D.pdf

29. National Ambulance Service. 2013 annual report. Accra (Ghana): Ministry of Health [Ghana]; 2014.

30. Bosson N, Redlener MA, Foltin GL, Raven MC, Foran MP, Wall SP. Barriers to utilization of pre-hospital emergency medical services among residents in Libreville, Gabon: a qualitative study. Am J Emerg Med. 2013;3(4):172-177. CrossRef

\section{Peer Reviewed}

Received: 2015 Jun 5; Accepted: 2015 Oct 9

Cite this article as: Mould-Millman N-K, Rominski SD, Bogus J, Ginde AA, Zakariah AN, Boatemaah CA, et al. Barriers to accessing emergency medical services in Accra, Ghana: development of a survey instrument and initial application in Ghana. Glob Health Sci Pract. 2015;3(4):577-590. http://dx.doi.org/10.9745/GHSP-D-15-00170.

(c) Mould-Millman et al. This is an open-access article distributed under the terms of the Creative Commons Attribution License, which permits unrestricted use, distribution, and reproduction in any medium, provided the original author and source are properly cited. To view a copy of the license, visit http://creativecommons.org/licenses/by/3.0/. When linking to this article, please use the following permanent link: http://dx.doi.org/10.9745/GHSP-D-15-00170. 